\title{
Simultaneous onset of malignant hypertension in identical twins
}

\author{
P. J. Lewis, D. F. J. Archer, and A. Breckenridge \\ From the Department of Clinical Pharmacology, Hammersmith Hospital, London
}

The case is described of a young man with malignant hypertension whose asymptomatic identical twin was also found to have malignant hypertension.

In recent years controversy has arisen concerning the nature of heredity in essential hypertension. Platt (1963) proposed a single gene inheritance, while Pickering (1968) put forward evidence that essential hypertensives differ only quantitatively from the normal population, and that blood pressure was inherited polygenically.

However, whatever the mode of inheritance, essential hypertension is heritable, and this case presents a striking example.

\section{Case report}

J.R., a mechanical engineer of 29, was without symptoms but found to be hypertensive when medically examined before emigration. He was treated with bethanidine for three months but then defaulted from follow-up. When referred to hospital, he had taken no treatment for a month. His only complaint was that over the last three years he had experienced intermittent haematospermia.

His blood pressure was $240 / 160 \mathrm{mmHg}$ and the fundi showed papilloedema, linear haemorrhages, and several cotton wool spots. Investigation showed left ventricular hypertrophy on chest $x$-ray and electrocardiogram $(\mathrm{RV} 5+\mathrm{SVI}=5.0 \mathrm{mV})$. The blood urea was $48 \mathrm{mg} / 100 \mathrm{ml}$ and there was proteinuria of $0.5 \mathrm{~g} / 24$ hours. Urine cultures, vanillyl mandelic acid excretion, and an intravenous pyelogram were normal. Renal size was: left, $12.5 \mathrm{~cm}$, right $11.5 \mathrm{~cm}$.

During his hospital admission, the patient was visited by his twin brother, A.R., a freelance designer. The brothers were known as identical (Fig. I) but lived some distance apart and had not seen each other for about a year. A.R. had also been troubled by intermittent hae-

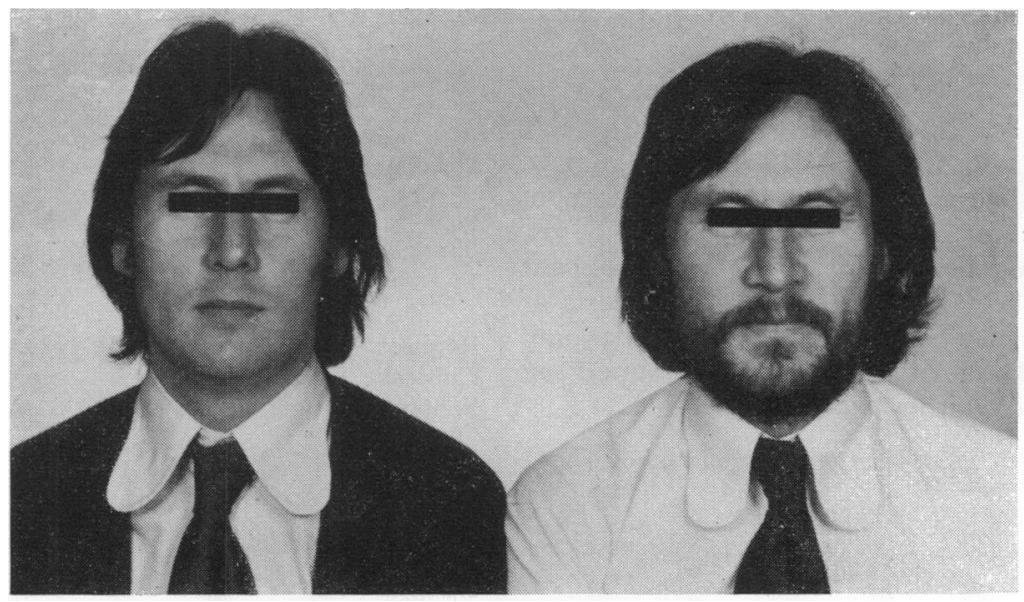

FIG. I The twins, A.R. and F.R. 

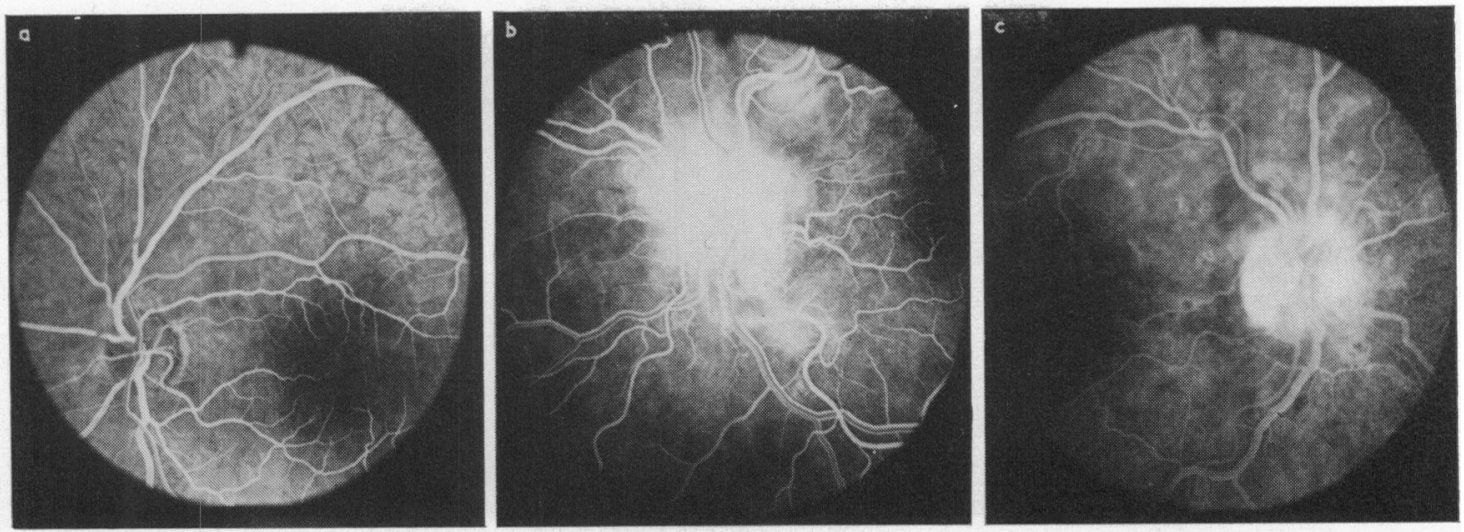

FIG. 2 Fluorescein angiograms. (a) Normal - no leakage of dye. (b) Left fundus of J.R., showing extensive leakage of the dye from vessels on the disc. (c) Right fundus of A.R., showing leakage of dye from disc vessels indicating papilloedema.

matospermia but was otherwise without symptoms. On examination, he was found to have a blood pressure of $220 / 160 \mathrm{mmHg}$. The fundi did not show haemorrhages but there were hard exudates present. Both optic discs had indistinct margins and were pink. Fluorescein angiography was performed, and this confirmed papilloedema showing leakage of dye from the disc. The fluorescein angiograms of both patients and a normal appearance for comparison are shown in Fig. 2a, b, and c.

Investigation of A.R. showed left ventricular hypertrophy on chest $x$-ray and electrocardiogram (RV5 + $S V_{I}=5.5 \mathrm{mV}$ ). The blood urea was $48 \mathrm{mg} / \mathrm{ro0} \mathrm{ml}$ and their proteinuria was of $\mathrm{I} \cdot 4 \mathrm{~g} / 24$ hours. Urine cultures and vanillyl mandelic acid excretion were normal, but the intravenous pyelogram showed somewhat contracted kidneys, with renal sizes: left II $\cdot 3 \mathrm{~cm}$, right $10.8 \mathrm{~cm}$.

No cause was found for the haematospermia. Blood typing, carried out by the Blood Group Reference Laboratory, Lister Institute, London, showed the twins identical for the nine blood groups determined.

\section{Discussion}

Several studies have shown close concordance of blood pressure in identical twins (Smirk, I957). However, simultaneous onset of the malignant phase has not been reported. In Platt's reports of identical twins with hypertension (Platt, I963) only in one pair did malignant hypertension supervene in both, and then with a two-year interval.
Platt used his cases to support a single gene hypothesis for essential hypertension. However, taken in isolation, twin concordances for blood pressure argue only for a genetic basis versus an environmental one. Other data, particularly the survey of Miall and Oldham (1963), indicate that the inheritance of arterial pressure is quantitative or polygenic.

The simultaneous occurrence of malignant hypertension in these patients is an unusual manifestation of the concordance of blood pressure in identical twins and underlines the role of heredity in essential hypertension.

P. J. L. is Hauff Fellow of the National Kidney Research Fund.

\section{References}

Miall, W. E., and Oldham, P. D. (1963). The hereditary factor in arterial blood-pressure. British Medical fournal, $\mathbf{1}, 75$. Pickering, G. W. (1968). High Blood Pressure, 2nd ed. Churchill, London.

Platt, R. (1963). Heredity in hypertension. Lancet, I, 899.

Smirk, F. H. (1957). High Arterial Pressure. Blackwell, Oxford.

Requests for reprints to Dr. P. J. Lewis, Department of Clinical Pharmacology, Royal Postgraduate Medical School, Hammersmith Hospital, London W.r2. 